\title{
Ocupação criativa: arte infantil decora o Hospital Universitário Pedro Ernesto
} Creative Occupation: children's art decorates Pedro Ernesto University Hospital

Candida Mirian Vasconcelos dos Santos ${ }^{1}$, Maira Torres Ruiz Martins ${ }^{2}$, Ana Joaquina Antunes Ferreira ${ }^{3}$

1 Assistente Social. Universidade Veiga de Almeida (UVA), Brasil. E-mail:candidamirian@ig.com.br

2 Psicóloga. Universidade Federal do Rio de Janeiro (UFRJ), Brasil. E-mail:mtruizmartins@hotmail.com

3 Arteterapeuta. Universidade Candido Mendes (UCAM), Brasil. E-mail:anajoatelier@terra.com.br

Recebido em: 31/03/2015 | Aprovado em: 14/07/2015

DOI: $10.12957 /$ interag.2015.15853

\section{Resumo}

Esse trabalho traz o relato de experiência vivenciada com a construção de painéis criativos elaborados a partir da intervenção da equipe da Brinquedoteca do Hospital Universitário Pedro Ernesto - HUPE, tendo como suporte os desenhos das crianças que frequentam a Brinquedoteca do HUPE. Nosso objetivo foi de provocar uma interferência criativa no ambiente hospitalar usando a arte como um caminho para se chegar à sensibilização e à humanização, transformando o ambiente hospitalar em um espaço mais acolhedor. Realizada a análise dos dados, três núcleos de sentido se destacaram: uso de material reciclado, a confortabilidade do ambiente e a humanização. Considerando esses temas, pudemos constatar que os painéis cumpriram seu objetivo ao promover a integração dos espaços hospitalares, transformando 0 frio cenário em um ambiente divertido e descontraído, sensibilizando as pessoas que ali atuam e buscam atendimento e promovendo uma ambiência mais acolhedora e saudável.

Palavras-chave: Humanização; Brinquedoteca hospitalar; Arte.

Área temática: Saúde e educação.

Linha de extensão: Saúde da Família.

\begin{abstract}
This is a report on the experiment with the "building of creative frames", conducted by the Toy Library of Pedro Ernesto University Hospital - HUPE team. The experiment was based on drawings by children who attend HUPE's Toy library. Our goal was to start a creative interference in the hospital by using art as a way of reaching awareness and humanization, transforming the hospital environment in a warmer space. Data were collected and analysed and three "spaces of sensibility" were found: the use of recycled material, the comfort of the environment and the humanization. According to the results of this study, it appears that the creative frames have achieved the purpose of promoting ideal integration among the different areas of the hospital, turning the cold scenario into a pleasant and relaxed space, bringing awareness to people who work or seek care there and leading into the development of a nurturing and healthier environment.
\end{abstract}

Keywords: Humanization; Hospital toy library; Art.

\section{Introdução}

Inspirados na atual política de sustentabilidade do HUPE e sem esquecer os princípios do HumanizaSUS, aproveitamos a realização do 49a Congresso Científico, cujo tema foi "Saúde da Criança" e criamos painéis decorativos para os corredores da Instituição, usando materiais reciclados e sobras da gráfica da Universidade do Estado do Rio de Janeiro - UERJ, tais como pôsteres, revistas e outros. Nosso objetivo foi, não só, mostrar a possibilidade da transformação do material descartado, mas também, provocar uma interferência criativa no ambiente hospitalar usando a arte como um caminho para se 
chegar à sensibilização e à humanização, transformando o ambiente hospitalar em um espaço mais acolhedor.

A Brinquedoteca do HUPE investe na ideia de uma sociedade sustentável mais harmônica, alegre e ética, exercitando os verbos reduzir, reutilizar, reciclar e recriar em suas atividades criativas.

Refletindo sobre os conceitos - sustentabilidade e humanização - percebemos que ambos estão relacionados a outro conceito de ampla dimensão - o cuidado. Cuidado esse que envolve o cuidado com o outro, consigo mesmo, com o planeta, com o universo. Ação complexa com repercussões múltiplas nas diversas redes de relações e inter-relações.

$\mathrm{BOFF}^{1}$ nos lembra que "Cuidar é mais que um ato é uma atitude de ocupação, preocupação de responsabilidade e de envolvimento afetivo com o outro”.

Pensando assim, a Brinquedoteca do HUPE propôs uma intervenção artística no espaço hospitalar, nas paredes dos longos corredores da Instituição e transformar esse espaço frio e triste em um cenário lúdico, agradável e divertido.

Norberg-Schulz ${ }^{2}$ nos traz o genius loci, espírito que dava vida às pessoas e aos lugares, acompanhando-os do nascimento à morte, determinando seu caráter e essência. Os antigos prezavam a prática de entrar em acordo com o genius da localidade onde viviam, uma vez que a sua sobrevivência dependia de uma boa relação com o lugar, no sentido físico e psíquico.

Outro ponto a se destacar diz respeito aos conceitos de "espaço" e "caráter" onde o primeiro indica a organização tridimensional dos elementos que formam um lugar e o segundo se refere a atmosfera geral que é a propriedade mais abrangente de um lugar. Logo, a atmosfera de um lugar é marcada por coisas concretas como forma, textura, cor e por sua essência, sua memória, seu uso, tradição e história. "Espaço" e "caráter" associados vão implicar no espaço vivenciado, no espaço reconhecido e identificado. 
Ambiente amplo, com extensos corredores e inúmeras portas onde, em sua maioria, imperam cores frias e uma atmosfera estéril é, geralmente, a imagem de um hospital. Lugar onde, em suas paredes, perpassam histórias de dor, de ansiedade, de angustia, de morte, muito mais do que histórias de cura. Em um espaço assim, a orientação e a identificação do sujeito estão prejudicadas, uma vez que há falta de familiaridade com o ambiente, com a história do lugar.

Logo, nos diz Arruda ${ }^{3}$

\footnotetext{
Adentrar o hospital é inserir-se em outra lógica de habitar. Lógica estruturada em formas de relacionamento interpessoal e de edificação bem diferentes daquelas residenciais domésticas, em que vivemos no dia-a-dia.
}

São edificações totalmente desconhecidas onde, não há indícios de coisas do cotidiano pertinentes à vida do sujeito. Para que essa identidade se forme é necessária a presença de símbolos, imagens que remetam ao cotidiano, a valores, afetos e outras percepções comuns a todos.

Norberg-Schulz ${ }^{2}$, citando Lynch, vai dizer que para o sujeito conquistar uma base de apoio existencial, ele deve ser capaz de saber onde está, (orientar-se), do mesmo modo que necessita identificar-se com o ambiente (como está). A percepção da inter-relação desses elementos vai formar uma "imagem ambiental" que conferirá ao sujeito uma sensação de segurança emocional, de pertencimento e acolhimento.

Assim, pensar o espaço hospitalar é pensar o espaço social onde nos movemos enquanto profissionais da área de saúde e/ou sujeitos em busca de atendimento terapêutico, espaço que afetamos e que por ele somos afetados.

\section{Metodologia}

Situado no bairro de Vila Isabel, o Hospital Universitário Pedro Ernesto, em seu Ambulatório de Pediatria atende crianças de 0 a 12 anos, nas várias clinicas, de 2a a 6 eeira, nos períodos da manhã e tarde. A construção dos painéis envolveu as crianças que frequentam a Brinquedoteca do HUPE enquanto esperam para serem atendidas no Ambulatório, sendo que a participação nessa atividade foi voluntária e sempre 
acompanhada pela equipe da Brinquedoteca. Toda essa atividade durou 3 meses, entre a autorização e a colocação nas paredes.

Importante ressaltar que tal proposta foi aceita pela comissão científica do $49^{\circ}$ Congresso Cientifico e pela direção da Instituição que muito facilitou a realização desta iniciativa.

Os painéis foram criados a partir da ideia dos bonecos de recorte que fazem parte da memória afetiva de todos nós. São figuras que remetem à infância e evocam sentimentos que acalentam, consolam e proporcionam bem-estar; logo, serviriam para abrandar a aridez dos corredores, ao mesmo tempo, que poderiam auxiliar, de modo lúdico e divertido na sinalização dos espaços destinados ao saber. Os painéis teriam ainda mais essa função, a de indicar as salas e anfiteatros onde se realizariam as palestras e apresentações do Congresso.

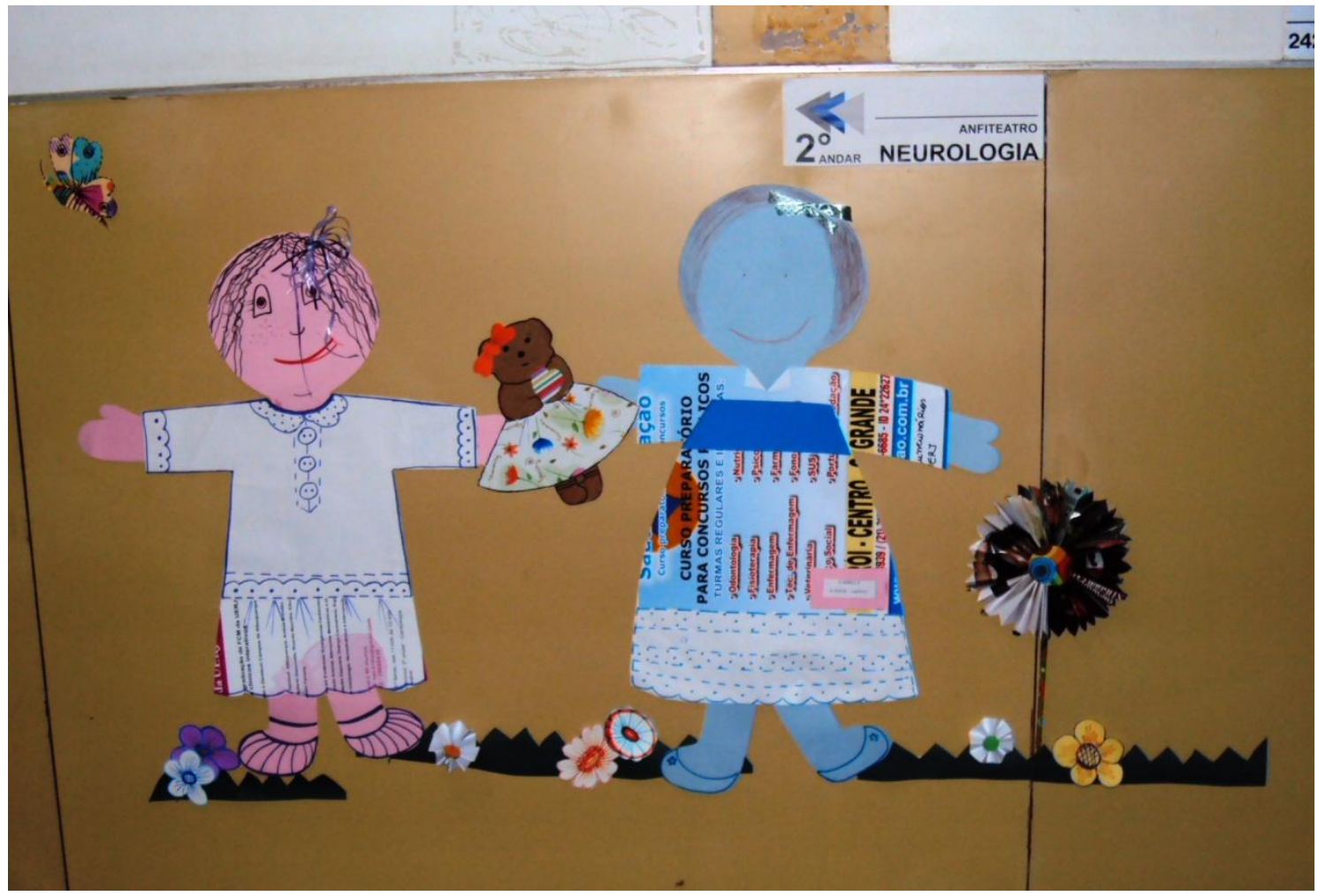

Figura 1. 


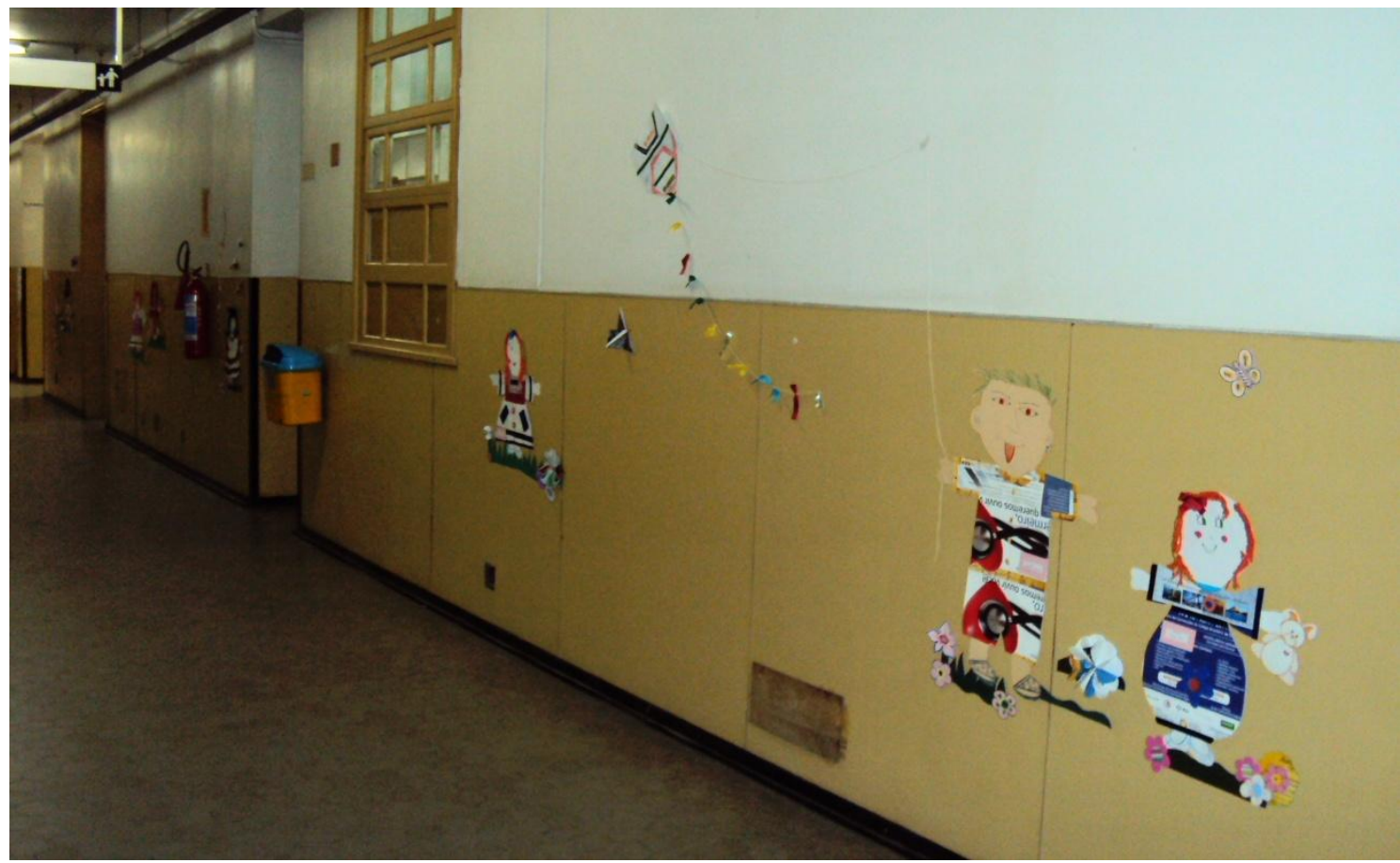

Figura 2.

Às crianças foi dito que iríamos fazer painéis com desenhos de bonecos para serem colocados nos corredores do Hospital durante o Congresso. A partir de sucatas de diversas origens, tais como: rejeitos da gráfica da UERJ, jornais, pôsteres, panfletos e revistas, grandes contornos de face feitos pelas Brinquedistas foram disponibilizados. A partir daí, cada criança pode criar seu próprio desenho, livre e espontaneamente, da maneira que imaginasse, fosse com hidrocor, lápis cera, lápis de cor ou usando colagens com os materiais disponíveis.

Prontas as faces, a equipe da Brinquedoteca criou corpos para os bonecos, que na maioria das vezes, ainda sofriam novas intervenções das crianças. Foram horas divertidas e intensas de criação, onde todos puderam vivenciar a arte.

Bonecos prontos, foi a vez de colocá-los nas paredes. Nesse momento surgiu a ideia de se adicionar alguns complementos. E, assim pequenas borboletas, pássaros, flores, bolas, carrinhos... ajudaram a compor os diversos painéis. Era um criar e recriar constante onde 
a arte pode ser realmente vivenciada, pois segundo Luigi Pareyson ${ }^{4}$ arte "é um tal fazer que, enquanto faz, inventa o por fazer e o modo de fazer”.

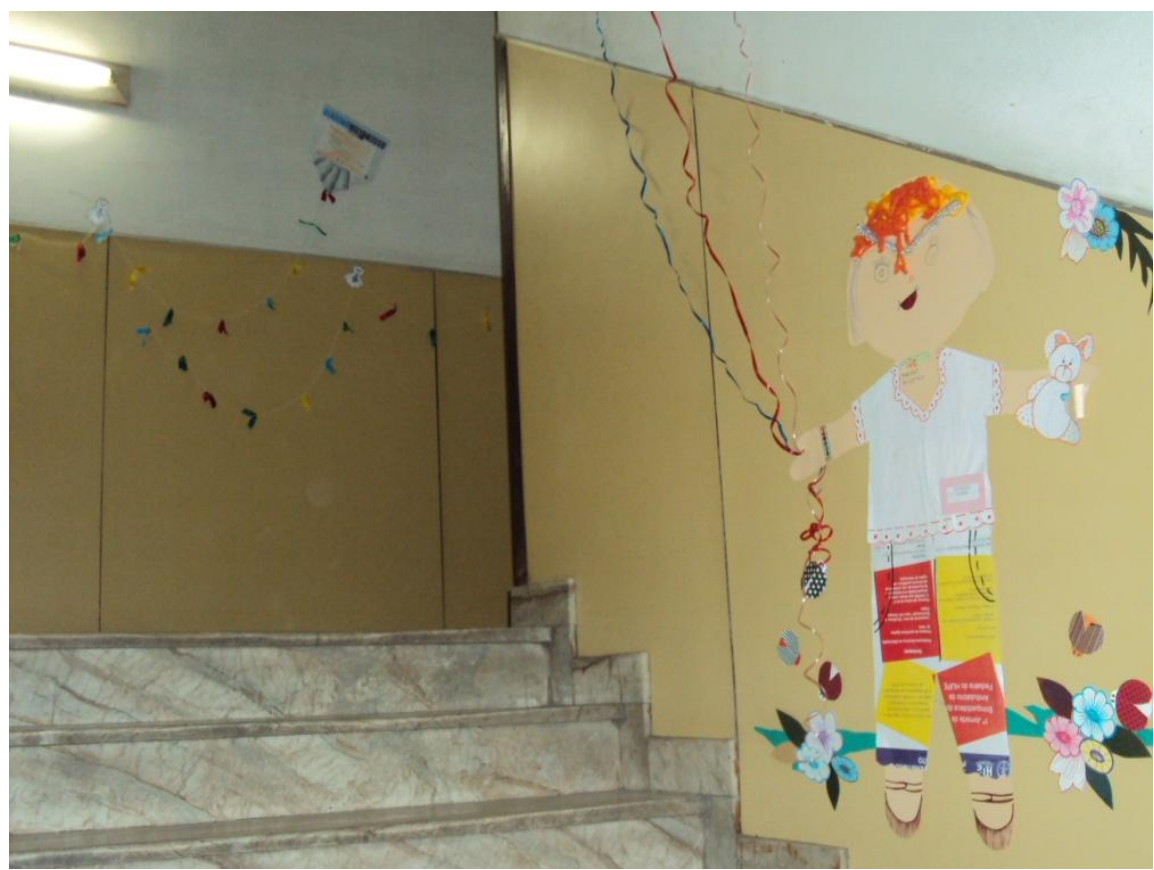

Figura 3.

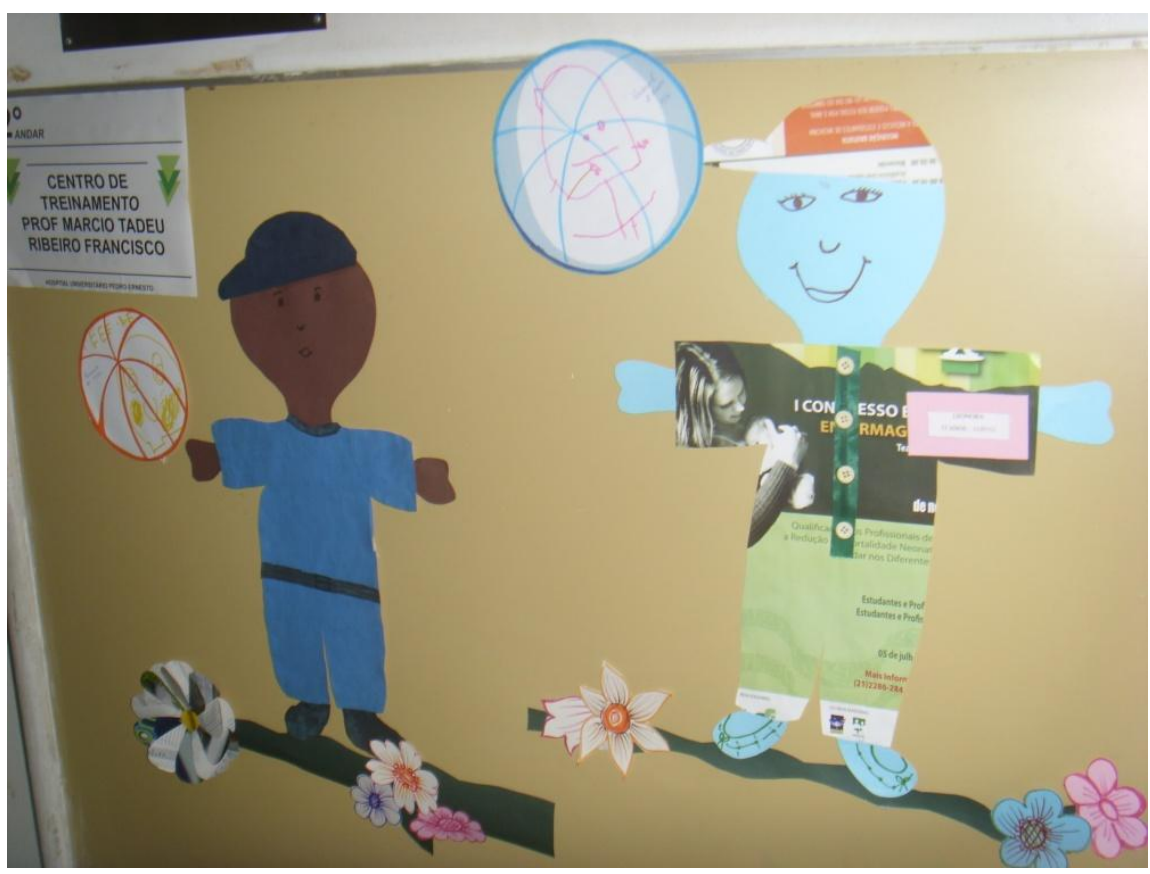

Figura 4. 
Tendo em vista as múltiplas dimensões, implicações e inter-relações desse trabalho, decidimos fazer uma pesquisa qualitativa para saber a opinião das pessoas que transitariam pelos corredores da Instituição, sobre a sensação que tais painéis poderiam provocar.

Nesse levantamento procuramos verificar se as intervenções criativas realizadas nas paredes da instituição possibilitariam atenuar a sensação de distanciamento e frieza que perpassa o espaço hospitalar. Para tal, folhetos foram entregues aleatoriamente, contendo as seguintes questões norteadoras e impressões: É participante do Congresso? Qual sua Universidade e curso? É funcionário, qual o seu setor? Já conhecia o HUPE? O que você pensa a respeito das interferências lúdicas nos corredores do hospital realizadas no Congresso?

\section{Análise e interpretação de dados}

Participaram dessa pesquisa, 87 sujeitos entre alunos, professores, funcionários e visitantes de ambos os sexos, escolhidos aleatoriamente, não havendo necessidade da identificação dos participantes.

Uma vez recolhido todos os questionários, foi realizada a análise dos dados e três núcleos de sentido se destacaram.

\section{- Reciclagem}

O uso de material de sucata nas intervenções criativas chamou atenção como podemos ver nesses excertos:

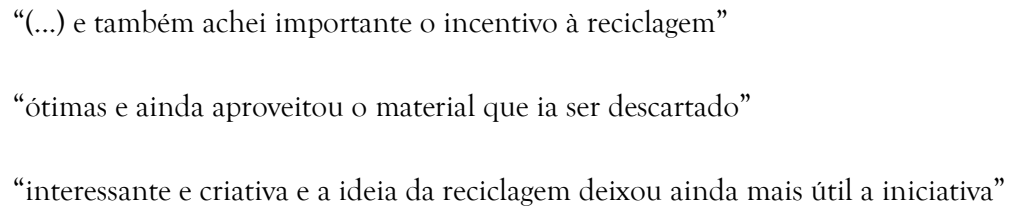

Em nossas incursões buscamos dar uma nova utilidade ao material descartado. A reciclagem é uma solução ecológica que contribui para o cuidado da vida de nosso 
planeta. Ao mesmo tempo, trabalhar com a sucata permitiu às crianças ampliar os canais de sensibilização, compreensão e responsabilidade do seu papel como seres viventes desse planeta.

Outro fator importante é que a curiosidade é uma característica natural da criança e a sucata oferece um mundo de possibilidades de criação e transformação ao criar novas funções para os objetos. Na atividade sugerida, as crianças motivadas mergulharam na proposta, usando com liberdade toda sua capacidade imaginativa, expressando seus sentimentos, desejos, ideias e fantasias nos bonecos que criaram.

\section{- Genius Loci}

Como vimos anteriormente, o espaço nunca é neutro, cada espaço possui uma "identidade" própria que vai transmitir um sentido, uma qualidade, um valor, uma sensação, limites e possibilidades que muitas vezes, acontece de maneira inconsciente. Percorrer os longos corredores de um hospital é sempre monótono e angustiante, não há qualquer estímulo visual agradável, ao contrário, destacam-se sentimentos como a dor, o sofrimento, o medo, o que implica em uma seriedade e frieza que contagia todos que ali trabalham ou buscam tratamento.

Seguindo esse viés, a Política Nacional de Humanização traz o conceito de confortabilidade. Lembra que o sujeito ao entrar em uma instituição de saúde - tanto usuários quanto funcionários e profissionais - são suscetíveis a perder suas referências sobre seu cotidiano, sua cultura e seus desejos, uma vez que "arriscam-se a deixar do lado de fora tudo que é relativo ao seu mundo, e podem perder as referências" ${ }^{5}$. Nesse sentido, segue dizendo que:

Pensar a confortabilidade dentro do conceito de ambiência é também resgatar esse vínculo para junto do processo de produção de saúde, construindo-se um território onde usuários e trabalhadores identifiquem seu mundo e suas referências nos espaços de cuidado e atenção à saúde.

Tais colocações foram vivenciadas pelos sujeitos de nossa pesquisa, que sinalizaram como o ambiente pode influenciar e ser influenciado, numa série de relações e inter-relações. 


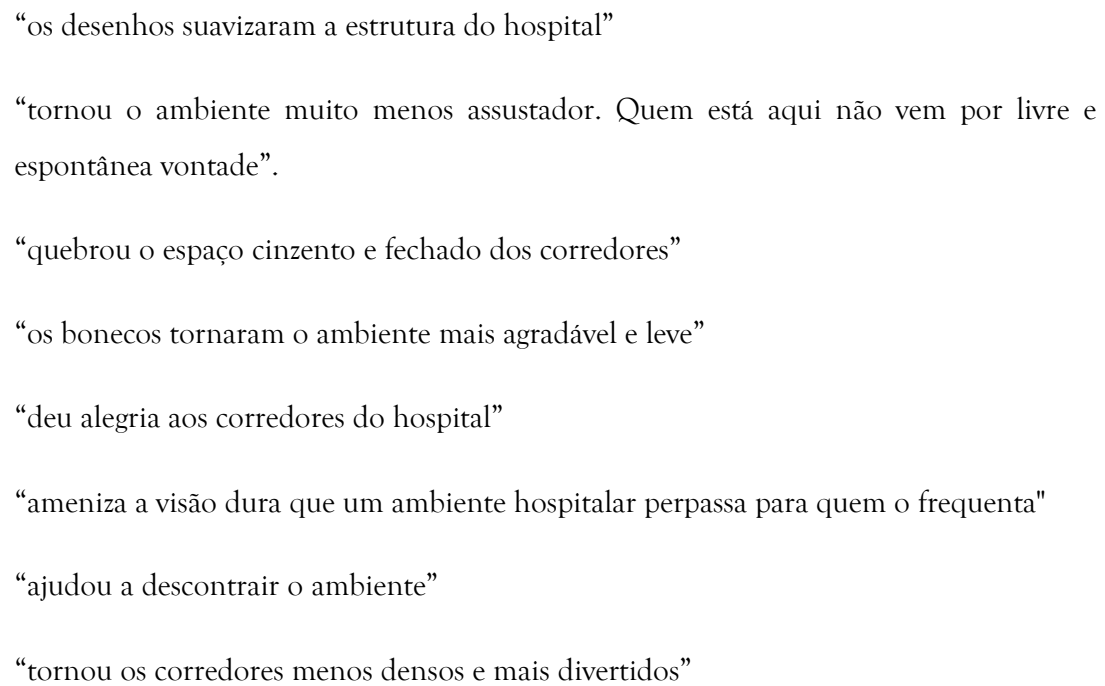

Vemos nesses fragmentos que a existência de símbolos associados ao cotidiano, imagens de fácil identificação, ligadas a determinadas vivências infantis, promoveram uma sensação de proximidade, de identidade, o que contribuiu para a sensação de segurança, pertencimento e vinculação. Daí nossa escolha pelos bonecos de recorte e demais símbolos que compuseram os painéis, pois estes trouxeram leveza e alegria ao espaço, tanto por suas cores e formas, quanto por serem figuras primitivas, desenhos infantis, ingênuos, familiares a qualquer sujeito, o que facilitou o reconhecimento, promovendo uma identificação com o lugar.

\section{- Humanização}

Humanizar implica no desenvolvimento de algumas características essenciais à vida humana, como a sensibilidade, a ética e a solidariedade para com os outros. O Programa de Humanização envolve tanto aspectos técnicos quanto relacionais e afetivos e um desses aspectos diz respeito à promoção de uma "ambiência acolhedora e confortável". Tal sensação foi observada pelos sujeitos que vivenciaram sentimentos de proximidade, integração e acolhimento como podemos ver nesses fragmentos:

\footnotetext{
"foi uma conduta interessante de aproximar as pessoas";

“tornaram o ambiente mais agradável e leve com mais integração das pessoas com o hospital";
} 
"alem de promover a troca de informação, desenvolve o relacionamento entre os diversos setores";

"tornaram o hospital mais acolhedor, passou a ideia de humanização do atendimento";

"importantíssimo investimento para criar um ambiente mais acolhedor diante de sua especificidade: paciente/servidor/aluno”.

Por meio desses relatos, observamos a importância do vínculo, do pertencimento, da comunicação e da interação no cenário hospitalar para o processo de humanização. Por outro lado, percebemos também a interessante teia de relações e inter-relações que a ambiência e a humanização evidenciaram, demonstrando as possibilidades de trocas de informação, integração, percepções e sensações que podem transformar o espaço hospitalar em um ambiente menos amedrontador, mais acolhedor e receptivo.

\section{Considerações finais}

Acreditamos que a experiência com os painéis lúdicos criativos foi bastante positiva, uma vez que os objetivos propostos foram alcançados. Foi possivel transformar o frio cenário hospitalar em um espaço agradável, divertido, descontraído que convidava as pessoas a estarem mais próximas uma das outras.

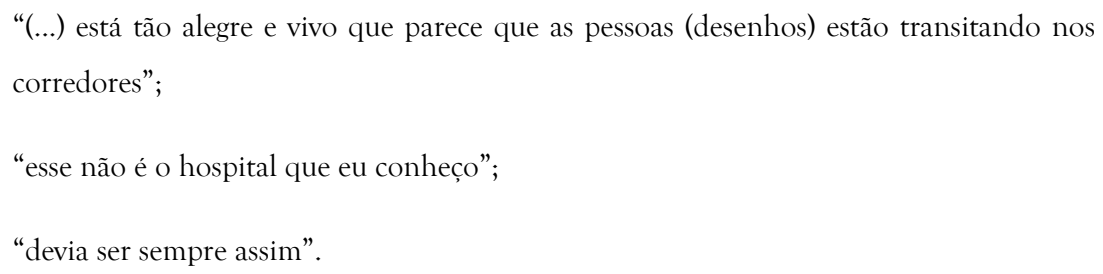

Entendemos que a ideia de humanização está relacionada à dimensão de cuidar, que, por sua vez, está ligada à sensação de acolhimento que o espaço pode produzir. Tais conceitos se expressam de modo relacional, afetando quem cuida e quem é cuidado.

Nessa proposta, vimos que a percepção do ambiente hospitalar, como frio, estranho e distante pode contribuir para o estabelecimento de situações iatrogênicas, uma vez que pode levar a um aumento da tensão, da ansiedade, do estresse e da angustia do paciente hospitalizado, dificultando a interação entre a equipe profissional e o paciente. Por outro lado, elementos como a alegria, as cores, o lúdico, a criatividade se mostraram essenciais, 
assim como as imagens e os símbolos familiares na promoção da vinculação e da apropriação do espaço institucional.

Destacamos também que a utilização da sucata na construção dos painéis foi bastante positiva. Entendemos que a manipulação desse material possibilitou a atenção para o cuidado e a preservação ambiental e, também, serviu como ação facilitadora para a ressignificação das vivências no ambiente hospitalar, implicando, consequentemente, na “reciclagem" emocional dos próprios sujeitos.

Os painéis criativos cumpriram seu objetivo ao promover a integração dos espaços hospitalares, sensibilizando as pessoas que ali atuam e buscam atendimento, ampliando o sentido de cuidado integral prestado ao paciente, seu acompanhante, equipe de saúde e funcionários.

\section{Contribuições das autoras}

Relato de experiência realizado em conjunto.

\section{Referências}

1. BOFF, Leonardo. Saber cuidar: Ética do Humano - Compaixão pela Terra, Petrópolis: Vozes, 1999, p.33.

2. NORBERG-SCHULZ, Christian. Fenomenologia do significado e do lugar. In: Kate Nesbitt (Org.). Uma Nova Agenda para a Arquitetura. Antologia Teórica 1965-1995. Cap. 9. Tradução Vera Pereira. São Paulo: Cosac Naify. 2a ed. Ver., 2008, p. 454.

3. ARRUDA, Daniel. A Psicologia Ambiental no Estudo da Inter-Relação PessoaAmbiente em Contexto Hospitalar. In: XIV Encontro Nacional da ABRAPSO, 2007, RJ. Anais do XIV Encontro Nacional da ABRAPSO, 2007. Disponível em: http://www.abrapso.org.br/siteprincipal/anexos/AnaisXIVENA/conteudo/pdf/trab_co mpleto_35.pdf Acesso em 26 de jan. 2015.

4. PAREYSON, Luigi. Os problemas da estética. São Paulo: Martins Fontes, 1989, p.32.

5. BRASIL. Ministério da Saúde. Secretaria de Atenção à Saúde. Núcleo Técnico da Política Nacional de Humanização. Ambiência/ Ministério da Saúde, Secretaria de Atenção à Saúde, Núcleo Técnico da Política Nacional de Humanização - 2a ed. Brasília: Editora do Ministério da Saúde, 2013. Disponível em: 
http://bvsms.saude.gov.br/bvs/publicacoes/ambiencia_reimp.pdf Acesso em 22 de jan. 2015. 